DOI: $10.21105 /$ joss. 01038

\section{Software}

- Review ¿

- Repository u

- Archive co

Submitted: 03 September 2018 Published: 19 November 2018

\section{License}

Authors of papers retain copyright and release the work under a Creative Commons Attribution 4.0 International License (CC-BY).

\title{
Gravity: Estimation Methods for Gravity Models in R
}

\section{Anna-Lena Wölwer ${ }^{1}$, Jan Pablo Burgard ${ }^{1}$, Joshua Kunst ${ }^{2}$, and Mauricio Vargas ${ }^{2}$}

1 Trier University 2 Pontifical Catholic University of Chile

\section{Summary}

Gravity models are used to explain bilateral flows related to the sizes of bilateral partners, a measure of distance between them and other influences on interaction costs. The underlying idea is rather simple. The greater the masses of two bodies and the smaller the distance between them, the stronger their attraction. For a state-of-the-art exposition about cross-sectional data see Wölwer, Breßlein, \& Burgard (2018).

The gravity package provides a wrapper of different standard estimation methods that can be quite difficult to implement in R ( $\mathrm{R}$ Core Team, 2018). By considering the descriptions and code of these methods, users get a comprehensive and application-oriented access, can see which methods may be suitable for certain research questions or data types, and can extend the code available for their specific research projects.

The functions included in this package are designed to be consistent with the Stata code used in Head \& Mayer (2014). Beyond offering an rstats open alternative to gravity model estimation in Stata we also provide cross-system compatibility that eases reproducible research for both researchers and students.

The current version of this package relies heavily on the rlang package (Henry \& Wickham, 2018) which provides tools to work with the core language features of base $\mathrm{R}$ and the tidyverse package (Wickham, 2017). As a result we provide fast model fitting computation while keeping correct handling and consistency when facing rank-deficient model matrices that base $\mathrm{R}$ handles well.

\section{References}

Head, K., \& Mayer, T. (2014). Chapter 3 - gravity equations: Workhorse,Toolkit, and cookbook. In G. Gopinath, E. Helpman, \& K. Rogoff (Eds.), Handbook of international economics, Handbook of international economics (Vol. 4, pp. 131-195). Elsevier. doi:10.1016/B978-0-444-54314-1.00003-3

Henry, L., \& Wickham, H. (2018). Rlang: Functions for base types and core $r$ and 'tidyverse' features. Retrieved from https://CRAN.R-project.org/package=rlang

R Core Team. (2018). R: A language and environment for statistical computing. Vienna, Austria: R Foundation for Statistical Computing. Retrieved from https://www. R-project.org/

Wickham, H. (2017). Tidyverse: Easily install and load the "tidyverse". Retrieved from https://CRAN.R-project.org/package=tidyverse

Wölwer, A.-L., Breßlein, M., \& Burgard, J. P. (2018). Gravity models in r. Austrian Journal of Statistics, 47(4), 16-35. doi:10.17713/ajs.v47i4.688 